\title{
RAMAN MICROSPECTROSCOPY STUDY OF CALCINED ELECTRICALLY CONDUCTIVE NANOCOMPOSITE POLYPYRROLE/GHASSOUL
}

\author{
${ }^{1}$ Pavlína PEIKERTOVÁ, ${ }^{1,2,3}$ Jonáš TOKARSKÝ, ${ }^{4}$ Lenka KULHÁNKOVÁ, \\ 'Kateřina MAMULOVÁ KUTLÁKOVÁ \\ ${ }^{1}$ Nanotechnology Centre, VŠB-Technical University of Ostrava, Ostrava, Czech Republic, EU, \\ pavlina.peikertova@vsb.cz, jonas.tokarsky@vsb.cz, katerina.mamulova.kutlakova@vsb.cz \\ 2IT4Innovations, VŠB-Technical University of Ostrava, Ostrava, Czech Republic, EU, \\ jonas.tokarsky@vsb.cz, \\ ${ }^{3}$ Institute of Environmental Technology, VŠB-Technical University of Ostrava, Ostrava, Czech Republic, EU, \\ jonas.tokarsky@vsb.cz, \\ ${ }^{4}$ Faculty of Materials Technology, VŠB-Technical University of Ostrava, Ostrava, Czech Republic, EU, \\ lenka.kulhankova@vsb.cz
}

https://doi.org/10.37904/nanocon.2020.3679

\begin{abstract}
Moroccan clay ghassoul (GHA) was used in preparation process of electrically conductive nanocomposite contained polypyrrole (PPy/GHA). Based on our previous studies on electrically conductive nanocomposites, the calcination may lead to formation of graphite and few-layer graphene. Prepared PPy/GHA nanocomposite was compressed to the square tablets which were calcined in an inert atmosphere at $1300{ }^{\circ} \mathrm{C}$. XRD measurements confirmed presence of graphite in the PPy/GHA sample. However, this method does not provide information about distribution of the graphitic and the few-layer graphene phases. Therefore, Raman microspectroscopy, which has an ability to distinguish the carbonaceous forms and allows showing their distribution on Raman spectral maps, was used as a major tool for the study of PPy/GHA. Several maps were created and studied. Spectral maps proved that the calcination leads to the formation of few-layer graphene on the surface of the tablet. Distribution of the graphitic phases was observed at the edge and on the surface of the tablet. Moreover, spectral maps were used to evaluate if and how the selected regions in one side correspond to each other.
\end{abstract}

Keywords: Ghassoul, polypyrrole, graphene, Raman microspectroscopy, electrical conductivity

\section{INTRODUCTION}

Polypyrrole (PPy) belongs to the groups of electrically conductive polymers, which can be used in various applications such as corrosion protectors or sensors (for biomolecules, VOCs, or gases) [1-6]. Arrangement of PPy chains may strongly affect its conductivity and can be performed by intercalation of the PPy into the interlayer space of clay matrix [7]. In our study, we used ghassoul (GHA), which is stevensite-rich Moroccan clay, as a carrier matrix for the PPy. Stevensite belongs to the trioctahedral smectite group and it is magnesium-rich phyllosilicate [8]. Prepared PPy/GHA nanocomposite powder was pressed into tablet and heat treated at $1300{ }^{\circ} \mathrm{C}$. Afterwards, the prepared calcined tablet was characterized by XRD and Raman microspectroscopy Aim of the study is to determine the presence and nature of graphitic structures formed during heat treatment, and to evaluate how homogeneous the sample is in terms of graphitic structure distribution. 


\section{EXPERIMENTAL}

Nanocomposite containing PPy and GHA was prepared in one-step process by oxidative polymerization of pyrrole $\left(\mathrm{C}_{4} \mathrm{H}_{5} \mathrm{~N} ; \geq 98 \%\right.$, Sigma-Aldrich, Czech Republic) with ferric chloride ( $\mathrm{FeCl}_{3}$; Merci (Czech Republic) in aqueous suspension of ghassoul (Societé du ghassoul et de ses dérivés Séfrioui, Morocco) which was sieved to obtain $<40 \mu \mathrm{m}$ size fraction. The initial materials were combined in mass ratio 1 (pyrrole) : $4.85\left(\mathrm{FeCl}_{3}\right)$ : $1.2(\mathrm{GHA})$. Black product which was obtained after $6 \mathrm{~h}$ of stirring were rinsed with distilled water, collected on filter, and dried for $24 \mathrm{~h}$ at $40^{\circ} \mathrm{C}$.

The prepared nanocomposite was ground to a fine powder in a mortar, and $28 \times 28 \mathrm{~mm}$ square tablets $(\mathrm{m}=3$ g) using ZWICK 1494 press for $10 \mathrm{~min}$ at $400 \mathrm{MPa}$ and room temperature $\sim 22{ }^{\circ} \mathrm{C}$ was prepared without any binder. Detailed description of the preparation process can be found in previous studies $[7,9]$.

Prepared tablet was heated in the inert atmosphere $(>99.9999 \% \mathrm{Ar})$ under constant overpressure $1.06 \cdot 10^{5} \mathrm{~Pa}$ in high-temperature tube resistance furnace (CLASIC CZ, spol. s.r.o., Czech Republic). The tablet was exposed to $1300{ }^{\circ} \mathrm{C}$ (temperature rise with step $5^{\circ} \mathrm{C} \cdot \mathrm{min}^{-1}$ ) for $1 \mathrm{~h}$. We present only results obtained from the heated tablet. Therefore, the designation PPy/GHA will further mean the heated sample.

Heated tablet was characterized by $\mathrm{X}$-ray diffraction $(\mathrm{XRD})$ in reflection mode in symmetrical Bragg-Brentano arrangement using Cu lamp $\left(\lambda\left(\mathrm{Cu}_{\mathrm{Ka}}\right)=0.15406 \mathrm{~nm} ; U=40 \mathrm{kV} ; I=40 \mathrm{~mA}\right)$ in Ultima IV diffractometer (Rigaku, Japan) equipped with scintillation detector. The phase composition of the sample was determined according to the ICDD PDF 2 Release 2014 database.

Raman spectral maps on the surface and on the edge of the tablet were measured using Smart Raman Microscopy System XploRA ${ }^{\text {TM }}$ (HORIBA Jobin Yvon, France). Laser $(532 \mathrm{~nm}, 100 \mathrm{~mW}$ ) was reduced to the $1 \%$ of initial intensity. Objective with magnification $50 \times$ and grating $600 \mathrm{gr} . / \mathrm{mm}$ were used for the maps collection in the selected regions $(21 \times 21 \mu \mathrm{m})$ with $1 \mu \mathrm{m}$ step.

\section{RESULTS AND DISCUSSION}

Diffraction pattern of the PPy/GHA is shown in Figure 1. As a result of the magnesium-silicate stevensite transformation, protoenstatite and forsterite were identified. Besides these phases, also graphite was determined in the diffraction pattern. Reflection at position 2 -Theta $=26.34^{\circ}$ reveals that its doo2 value is $d=3.38 \AA$. The broad reflection under $20^{\circ} 2$-Theta can be ascribed to a disordered carbon structure derived from PPy, which has not been transformed into graphite.

XRD proved the presence of the graphitic structure, but it is not able to determine how many disorders are in the graphitic structure, how the structure is distributed in the sample, and whether the structure consist only from graphite or whether also some form of graphene is present. Raman microspectroscopy is very useful tool for the characterization of the carbonaceous samples. Big advantage is due to its connection with microscope, which allows the generation of the spectral maps and moreover very valuable information of the graphitic structure can be deduced from the Raman spectra.

Carbonaceous samples has three main bands; $D$ (i.e. disorder), $G$ (i.e. graphitic), and 2D band (overtone of $D$ band). The most significant for the graphene determination is the $2 \mathrm{D}$ band [10], because its intensity may prove the presence of graphene. When intensity of $2 \mathrm{D}\left(\mathrm{I}_{2 \mathrm{D}}\right)$ is four times higher than the intensity of $G$ band $\left(I_{G}\right)$ [11], the presence of single-layer graphene can be suggested. Moreover, ratio of the intensities of the $D$ and $G$ bands $\left(I_{D} / I_{G}\right)$ show the degree of effects in the graphitic structure.

Raman spectral maps were collected from the three different regions on the surface and three different regions on the edge of the PPy/GHA tablet. And measured Raman spectra confirm the presence of the graphitic structure in the sample. But the spectra detected in the Raman maps show that the graphitic structure varies according the intensity of the 2D band (see Figure 2). Raman spectral maps from the surface and edge are 
shown in Figure 3 and four different colors are observable (as is shown in Figure 2). Black color means that the $2 \mathrm{D}$ band was not detected in this measured point. Blue color means that the $\mathrm{I}_{2 \mathrm{D}} / \mathrm{I}_{\mathrm{G}}$ is lower than 0.5 , green color means that the $0.5<\mathrm{I}_{2 \mathrm{D}} / \mathrm{I}_{\mathrm{G}}<1$ and red color means that the $\mathrm{I}_{2 \mathrm{D}} / \mathrm{I}_{\mathrm{G}}>1$. Exemplary spectra are shown in Figure 3. Few-layer graphene can be suggested in the red areas [12], where the intensity $\mathrm{I}_{2 \mathrm{D}} / \mathrm{I}_{\mathrm{G}}$ is higher than 1 , and in several cases almost reaches 2, in the case of shown Raman map from the surface (Figure 2, red spectrum).

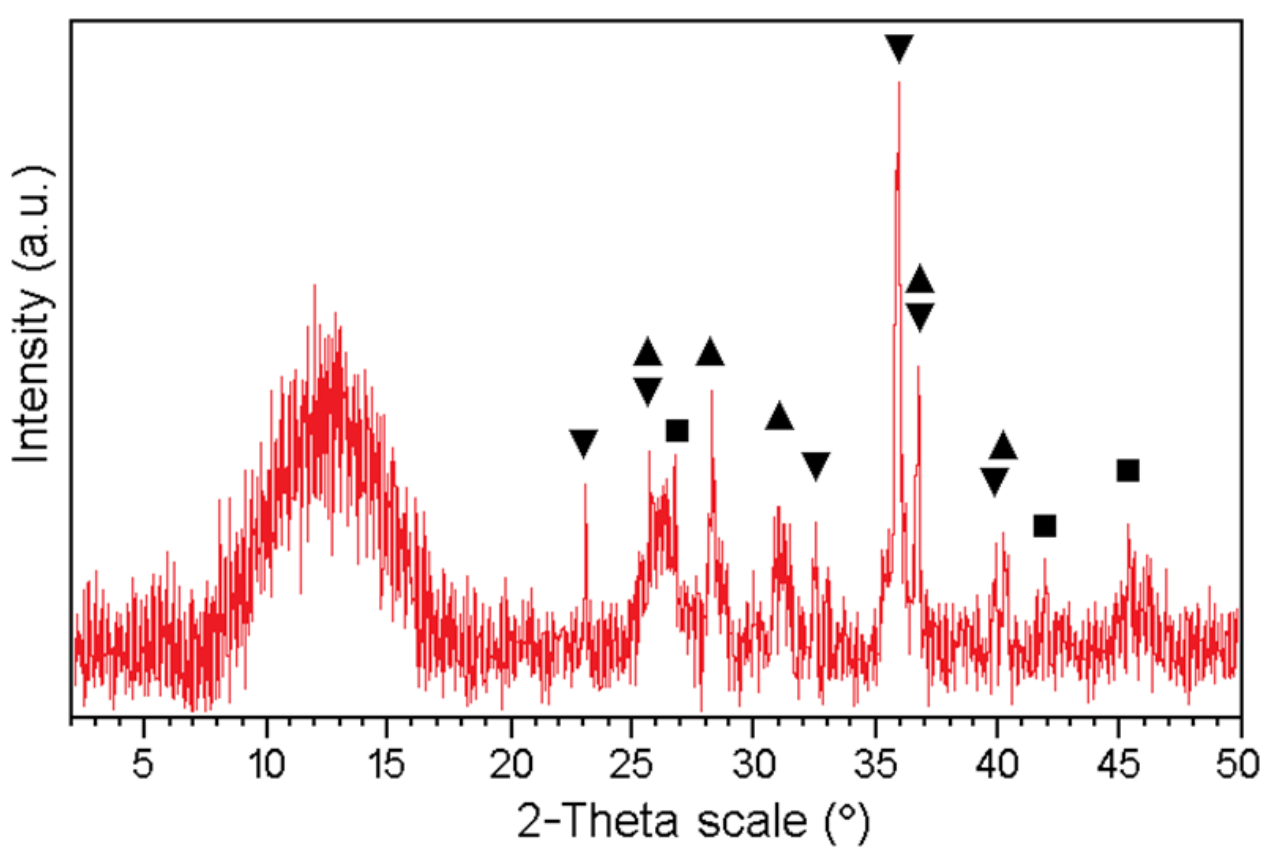

Figure 1 XRD pattern of PPy/GHA. a graphite, $\boldsymbol{\Delta}$ protoenstatite, $\boldsymbol{\nabla}$ forsterite

Raman spectral maps reveal the heterogeneity of the graphitic structure and also the difference between the surface and the edge of the tablets. On the surface was detected few-layer graphene $n<5$ ( $n=$ numbers of graphene layers), which are observable as red color in Figure 2 and Figure 3. Multi-layer graphene is connected to the green color [10]. Calculated ratios of $\mathrm{I}_{2 \mathrm{D}} / \mathrm{lg}_{\mathrm{G}}$ for the whole region are in Table 1 . There is very good correlation between the values from different regions on the surface/edge and copy the information from the Raman spectral maps, accordingly the higher values for the surface (presence of few-layer graphene) and lower for the edge.
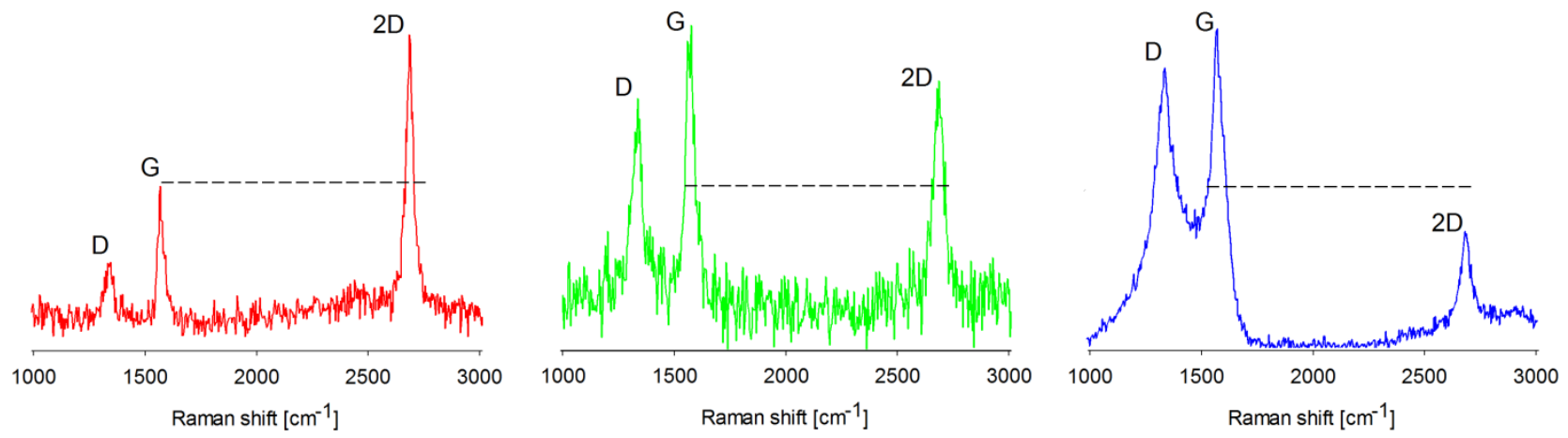

Figure 2 Chosen Raman spectra which show meaning of the colors of the maps (Figure 3) Red: $I_{2 D} / I_{G}>1$; green: $0.5<\mathrm{I}_{2 \mathrm{D}} / \mathrm{I}_{\mathrm{G}}<1$; blue: $\mathrm{I}_{2 \mathrm{D}} / \mathrm{I}_{\mathrm{G}}<0.5$ 

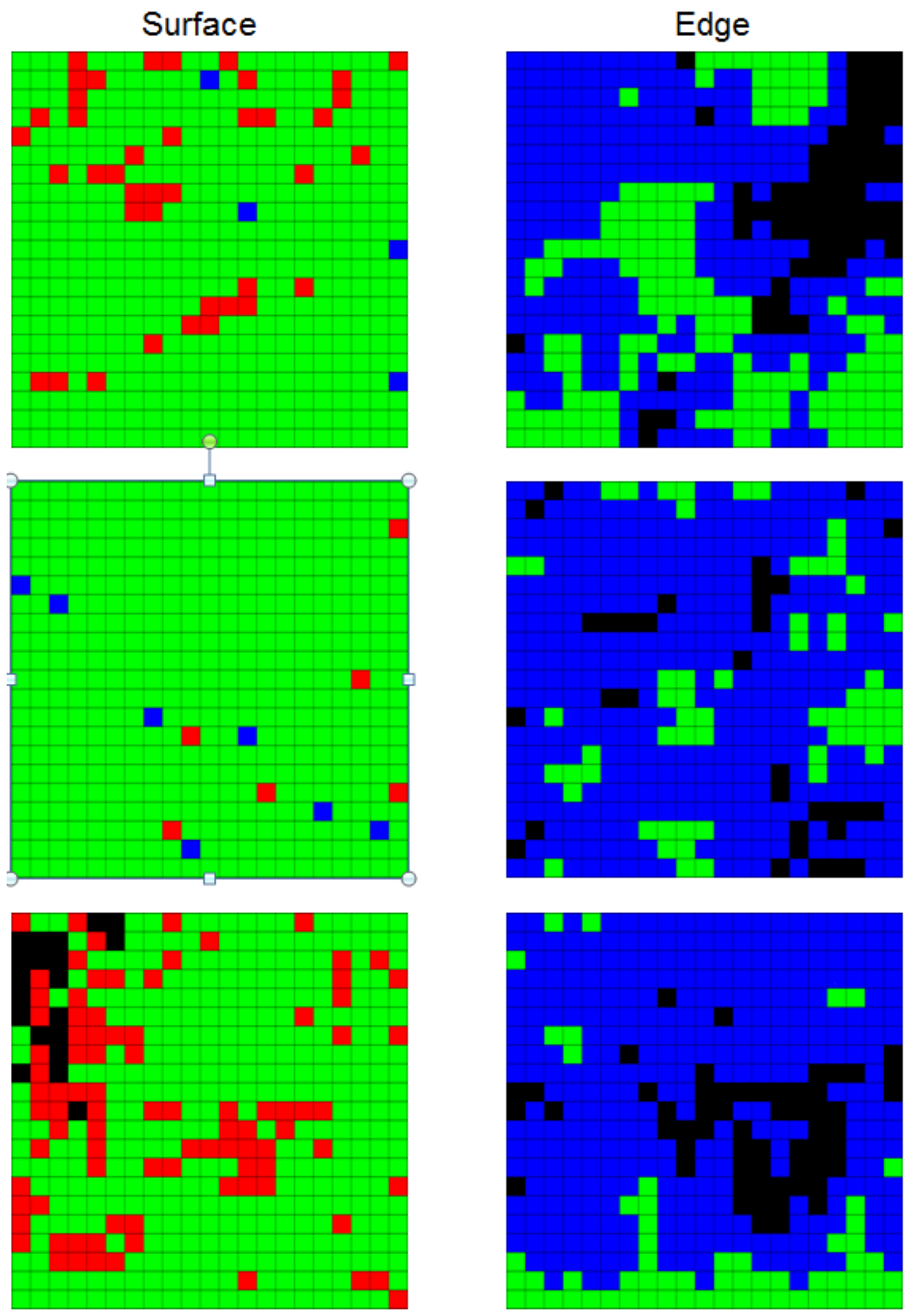

Figure 3 Raman spectral map of selected region $(21 \mu \mathrm{m} \times 21 \mu \mathrm{m})$ in the surface (left), and in the edge (right) of PPy/GHA tablet. Red: $\mathrm{I}_{2 \mathrm{D}} / \mathrm{I}_{\mathrm{G}}>1$; green: $0.5<\mathrm{I}_{2 \mathrm{D}} / \mathrm{I}_{\mathrm{G}}<1$; blue: $\mathrm{I}_{2 \mathrm{D}} / \mathrm{I}_{\mathrm{G}}<0.5$; black: no $2 \mathrm{D}$ band 
Table 1 Calculated values for intensity ratio $I_{D} / I_{G}$ and $I_{2 D} / I_{G}$

\begin{tabular}{|c|c|c|}
\hline & Surface & Edge \\
\hline \multirow{3}{*}{$\mathrm{I}_{2 \mathrm{D} / \mathrm{IG}_{\mathrm{G}}}$} & $0.82 \pm 0.14$ & $0.40 \pm 0.17$ \\
\cline { 2 - 3 } & $0.73 \pm 0.11$ & $0.37 \pm 0.12$ \\
\cline { 2 - 3 } & $0.90 \pm 0.20$ & $0.35 \pm 0.13$ \\
\hline \multirow{3}{*}{$\mathrm{I}_{\mathrm{D} / \mathrm{l} G}$} & $0.73 \pm 0.11$ & $0.82 \pm 0.16$ \\
\cline { 2 - 3 } & $0.83 \pm 0.12$ & $0.81 \pm 0.13$ \\
\cline { 2 - 3 } & $0.71 \pm 0.13$ & $0.88 \pm 0.11$ \\
\hline
\end{tabular}

Also the $\mathrm{ID}_{\mathrm{D}} / \mathrm{IG}_{\mathrm{G}}$ were calculated to determine the degree of disorders and surprisingly the values for the surface and the edge are pretty similar, although little bit lower for the surface (less defects), which is connected to higher appearance of few-layer graphene. From the results is clearly visible that the random selected regions express the character of the surface/edge and in terms of surface or edge the structure is relatively homogeneous.

\section{CONCLUSIONS}

The PPy/GHA nanocomposite was successfully prepared by heating at $1300{ }^{\circ} \mathrm{C}$ in inert atmosphere. XRD analysis revealed the presence of graphite in the structure of heated nanocomposite, which was confirmed by Raman microspectroscopy. Moreover, generated Raman spectral maps reveal differences between the edge and surface of the tablet, when the few-layer graphene with less than 5 layers was observed on the surface. Calculated $\mathrm{I}_{\mathrm{D}} / \mathrm{I}_{\mathrm{G}}$ reveals that the degree of defects is almost equal, but little bit lower for the surface. Taking into account the presence of forsterite and enstatite in heated PPy/GHA nanocomposite, the results suggest a promising way in which a ceramic material containing graphite and graphene prepared in situ from the polypyrrole could be achieved.

\section{ACKNOWLEDGEMENTS}

This work was supported by The Ministry of Education, Youth and Sports of the Czech Republic (projects SP2020/24, LQ1602, CZ.02.1.01/0.0/0.0/16_013/0001791).

\section{REFERENCES}

[1] GONZÁLEZ, M. B., SAIDMAN, S. B. Corrosion protection properties of polypyrrole electropolymerized onto steel in the presence of salicylate. Progress in Organic Coatings. 2012, vol. 75, no.3, pp. 178-183.

[2] BANDEIRA, R. M., van DRUNEN, J., GARCIA, A. C., TREMILIOSI-FILHO, G. Influence of the thickness and roughness of polyaniline coatings on corrosion protection of AA7075 aluminum alloy. Electrochimica Acta. 2017, vol. 240, pp. 215-224.

[3] KALANTAR-ZADEH, K. Polypyrrole nanofiber surface acoustic wave gas sensors. Sensors and Actuators $B$ : Chemical. 2008, vol. 134, no. 2, pp. 826-831.

[4] AKBARINEJAD, A., GHOORCHIAN, A., KAMALABADi, M., ALIZADEH, N. Electrospun soluble conductive polypyrrole nanoparticles for fabrication of highly selective n-butylamine gas sensor. Sensors and Actuators $B$ : Chemical. 2016, vol. 236, pp. 99-108.

[5] RAMANAVIČIUS, A., RAMANAVIČIENÉ, A., MALINAUSKAS, A. Electrochemical sensors based on conducting polymer-polypyrrole. Electrochimica Acta. 2006, vol. 51, no. 27, pp. 6025-6037.

[6] KOIRALA, K., SEVILLA III, F. B., SANTOS, J. H. Biomimetic potentiometric sensor for chlorogenic acid based on electrosynthesized polypyrrole. Sensors and Actuators B: Chemical. 2016, vol. 222, pp. 391-396. 
[7] VILÍMOVÁ, P., KULHÁNKOVÁ, L., PEIKERTOVÁ, P., MAMULOVÁ KUTLÁKOVÁ, K., KONíČKOVÁ, H., VALLOVÁ, S., PLAČEK, T., TOKARSKÝ, J. Effect of montmorillonite/polypyrrole ratio and oxidizing agent on structure and electrical conductivity of intercalated nanocomposites. Applied Clay Science. 2019, vol. 168, pp. 459-468.

[8] RHOUTA, B., KADDAMI, H., ELBARGY, J., AMJOUD, M., DAUODI, L., MAURY, F., SENCOCQ, F., MAAZOUZ, A., GERARD, J.F. Elucidating the crystal-chemistry of Jbel Rhassoul stevensite (Morocco) by advanced analytical techniques. Clay Minerals. 2008, vol. 43, no. 3, pp. 393-403.

[9] TOKARSKÝ, J., VILÍMOVÁ, P., PEIKERTOVÁ, P., MAMULOVÁ KUTLÁKOVÁ, K., KULHÁNKOVÁ, L. Stevensiterich Moroccan clay intercalated by polypyrrole: towards the enhancement of electrical conductivity. Journal of Nanoscience and Nanotechnology. 2019, vol. 19, no. 5, pp. 2821-2832.

[10] FERRARI, A.C., MEYER, J.C., SCARDACI, V., CASIRAGHI, C., LAZZERI, M., MAURI, F., PISANEC, S., JIANG, D., NOVOSELOV, K.S., ROTH, S., GEIM, A.K. Raman spectrum of graphene and graphene layers. Physical Review Letters. 2006, vol. 97, pp. 187401.

[11] TAN, P.H., HU, C.Y., DONG, J., SHEN, W.C., ZHANG, B.F. Polarization properties, high-order Raman spectra, and frequency asymmetry between stokes and anti-stokes scattering of Raman modes in a graphite whisker. Physical Review B. 2011, vol. 64, pp. 214301.

[12] GUPTA, A., CHEN, G., JOSHI, P., TADIGADAPA, S., EKLUND, P.C. Raman scattering from high-frequency phonons in supported n-graphene layer films. Nano Letters. 2006, vol. 6, 12, pp. 2667-2673. 